\title{
Leading in Higher Education with Emotional Competence
}

\author{
Osman Ferda Beytekin ${ }^{1}$ \\ ${ }^{1}$ Faculty of Education, Ege University, Izmir, Turkey \\ Correspondence: Osman Ferda Beytekin, Faculty of Education, Ege University, Izmir, Turkey. E-mail: \\ ferda.beytekin@ege.edu.tr
}

Received: July 5, $2021 \quad$ Accepted: August 3, $2021 \quad$ Online Published: August 15, 2021

doi:10.5539/hes.v11n3p116

URL: https://doi.org/10.5539/hes.v11n3p116

\begin{abstract}
The aim of this interpretative study was to find out how higher education administrators thought about emotional competence and what emotional competence ideas and skills they thought were essential for success. Specifically, the aim of this study was to get a better understanding of how administrators in departments of higher education may use their emotional skills to their benefit in their professions. In-depth interviewing takes one step further by focusing in considerable detail on the life experiences and social behavior of selected individual respondents in qualitative research. An in-depth interview was conducted for this qualitative research with eight experienced heads of departments who shared their experiences for a number of reasons. In order to get meaning from the narratives, certain techniques and templates were used. Purposive sampling was used in the 2019-2020 academic year for eight heads of departments at a public university in Izmir, Turkey, with an emphasis on phenomena relevant to the topic and at least four years of administration experience in selecting criteria. The key insight from the study's findings is that participants interpreted emotional competence to entail the ability for university administrators to develop connections by generating trust in order to lead their department. Having an open mind, having an optimistic attitude, being respectful, being inclusive, listening actively were all regarded as key subthemes by higher education administrators. Longitudinal or mixed methods studies, as well as demographic variations in leaders' use of emotional competencies, might be explored in future research.
\end{abstract}

Keywords: emotional competence, higher education administrators, leadership

\section{Introduction}

One of the most essential components of it is the individuals who make up the organizations. The reasons for human behavior and organizational behavior and the outcomes should then be investigated in order to properly comprehend them. Administrators, on the other hand, are the key elements in the organization's current and future. Administrators distinguish their organizations from others by their cultural values and emotional and social capabilities. The effectiveness of the administrators should not be judged solely on the fact that they are experts in their subjects. More importantly, they should be considered together with their success in managing their emotions and relationships with society. Education management has abandoned conventional management understanding from the top. The emotional and social components of human achievement in management techniques are increasingly being taken into account (Bauman, 2006). Proactive leaders can feel when it is the appropriate moment to have their organizations work together, and actively listening helps them to achieve their goals (Akyol \& Arslan, 2014). Understanding organizational behavior and management model effectiveness can help to forecast and analyze administrative behaviors, as well as emotional and social abilities, in a more simplified manner. Emotion and intelligence are essential for individuals, and they are equally essential for educational organizations, which are extremely significant because people are so important. The effectiveness of educational organizations, the use of appropriate human resources, and the development of successful management relationships are all factors to take into account. Based on rigorous research, it is shown that administrators with greater levels of emotional competence are more likely to perform better in the workplace, to be engaged, to make good decisions, to have better stress resistance, to handle conflict, to work well with others, and to be in positions of leadership (Beytekin \& Göktürk, 2012). Providing administrators with emotional competence training helps them to succeed in career advancement, leading to more positive outcomes.

Educators who work in educational organizations where management is highly essential are the ones who bear the greatest responsibility for the success or failure of their respective organizations. The ability to recognize and appropriately regulate one's own and others' emotions is a natural characteristic of those who are capable of 
becoming even more effective in terms of leadership. Effective leaders are those who are able to monitor the emotions of others and themselves, as well as those who are able to persuade as many people as possible. The ability of an individual to be aware of his or her own and others' emotions and to manage them properly is referred to as emotional and social skills (Goleman, 2006). The capacity of an administrator to manage successfully is one of the most important factors to consider when putting administrative processes into action. This is accomplished through the emotional and social capabilities of the manager. Leading by being conscious of their own sentiments allows those who can manage them to exert more self-control. By earning their followers' confidence and respect, they may establish themselves as role models for the rest of the organization. Additionally, leaders who are able to recognize and understand their followers' emotions are better able to comprehend their expectations and sensitivities, and they may serve as a source of inspiration for them. Individuals are valued, not only in a group, and those who can form one-on-one connections and put themselves in the shoes of others are valued. Leaders who get their act together can successfully manage their relationships (Barling, Slater, \& Kelloway, 2000).

In 2006, Goleman proposed the concept of emotional and social competence, which is based on his emotional intelligence model, which he articulated in 1995. Goleman (2006) describes emotional competence as an acquired talent based on emotional intelligence that results in performance in a unique role. The sub-dimensions of emotional competence are individual awareness and consist of self-management skills. In other words, emotional competence is the ability of an individual to be aware of his or her own emotions and to effectively manage them. According to Goleman (2006), social competence is defined as an individual's social awareness and ability to manage interpersonal relationships. As a result of his social skills, the administrator is sensitive to the emotions of others and can respond appropriately. Leaders manage their connections in such a way that they can understand people and be accurate in a variety of social settings, allowing them to be successful in establishing effective behavioral models at the appropriate time and location.

Universities, as higher education institutions and therefore their administrators, have to follow the latest developments of the era and improve themselves as required by their duties (Gumport and Sporn, 1999). This is only possible if their leadership skills are at a high level (Kezar, Lester, Carducci, Gallant \& McGavin, 2007). A primary focus of management at the university is leadership, activities such as research, learning, and instructing others, and helping people grow in their field (Knight \& Trowler, 2001). Higher education administrators, while fulfilling their responsibilities, have to take on many different roles. These are the dimensions of educators, leaders, and managers (Winston, Creamer \& Miller, 2001). Administrators form relationships with people, influence them, carry out their duties, organize the organization, and strive to achieve their goals. Leaders are effective when they integrate all employees into the organization's goals. Technical, interpersonal, and cognitive talents are, nevertheless, characteristics of effective leadership (Hoy \& Miskel, 2010), and emotional intelligence is also required for effective leadership in higher education. The competencies needed to involve individuals in this process are more than just having problem solving or cognitive skills. Research shows that there is a significant relationship between effective leadership behavior and emotional and social competencies (Beytekin \& Göktürk, 2012; Bauman, 2006; Goleman, 2006; Boyatzis \& Oosten, 2002; Gardner \& Stough, 2002; Barling, Slater \& Kelloway, 2000; Cherniss, 2000; Cooper \& Sawaf, 1997; Mayer \& Salovey, 1997). It is also essential for higher education administrators to discover answers to challenges they face, to make the best judgments in their relationships, and to have a thorough understanding of themselves and others around them.

The ability to identify the emotions of others around him and to build successful relationships with them is the cornerstone of social competence (Goleman, 2006). While cognitive and technical abilities are crucial for leadership, according to Goleman (2006), emotional leadership is the most significant component in effective leadership. Because of the various challenges they encounter, educational administrators, diverse expectations of workers, and jobs necessitate more social and emotional skills. Emotional intelligence has a significant impact on the behavior of effective managers and leaders (Mayer \& Salovey, 1997; Goleman, 2006). Goleman (2006) has explained emotional and social competencies as awareness, self-management, social awareness and relationship management in their sub-dimensions. Self-knowledge, awareness of one's own feelings and being able to manage them, is one of the cornerstones of emotional competence and social competence demonstrates one's ability to interact with others. Emotional competence leads to exceptional work performance. It is a learned skill based on emotional intelligence. In other words, emotional competence is demonstrated by the use of an individual's self-awareness and self-management skills at the appropriate time and place (Boyatzis, Goleman, \& Rhee, 1999). Emotional competence, according to Boyatzis et al. (1999), is defined as an individual's capacity to identify, comprehend, and use their emotions. Boyatzis states that the use of this talent was successful in achieving the organization's objectives. Through the use of an individual's social awareness and relationship 
management abilities, they are able to comprehend and model successful conduct in a variety of social settings at the appropriate time and place.

The topic of educational leaders' emotional intelligence has got a lot of attention recently. According to Goleman (2013), "directing attention is a key responsibility of leadership," and "to do so, leaders must learn to concentrate their own attention... an internal focus, a focus on others, and an outward focus". This remark is consistent with Salovey and Mayer's initial definition of emotionally intelligent individuals, which was "those who have the ability to self-assess and regulate their conduct in order to assist others" (1990). The Four-Branch Model of Emotional Intelligence was suggested by Salovey and Mayer (1990), showing four hierarchical areas or talents that characterize one's potential to be called emotionally intelligent: (1) how to recognize emotions, (2) how to express feelings, (3) how to comprehend emotions, and (4) how to deal with emotions. Salovey and Mayer (1990) suggested that individuals may, via special awareness of deficiencies and a concentration on each of these areas, both learn and grow their emotional intelligence skills. The researchers claimed by being self-concentrated and reflective, each leader and leader may act on his own understanding of emotionally smart behavior and subsequent progress. In that Goleman and Bar-on blend or 'freely described personality characteristics that might accompany intelligence', the mixed-models approaches taken by Goleman (2006) and Bar-On (2013) differ from those adopted by Salovey and Mayer (1990) in their model rather than the cognitive ability alone. Some of the features were "personal autonomy, self-respect and mood" (Sternberg, 2000). Sternberg also highlighted that "these mixed theories regard mental capacity and a range of other qualities as a single entity, such as motivation, state of consciousness and social engagement.

A leader's responsibility for influencing people positively through the application of emotional intelligence presents many challenges: How are leaders best able to learn to evaluate themselves and modify their own behavior? How do the leaders themselves identify the characteristics and abilities they have found necessary and beneficial in professional practice, among the diverse theories of emotional intelligence? Furthermore, how do educational leaders better educate managers for the management of the stress and conflict inherent in their jobs? How do these strategists help to build the capacities of emotionally aware administrators? As leaders at all organizational levels have begun to appreciate, managing people in an emotional environment necessitates a certain set of abilities, and this has sparked an interest in emotional competence among higher education leaders. Additionally, because colleges and universities are mostly focused on the people who work in them, university leaders may learn about their emotional competency and how to effectively apply it to their jobs as leaders.

The research (Bar-On, 2013; Beytekin \& Göktürk, 2012; Bauman, 2006; Goleman, 2006; Boyatzis \& Oosten, 2002; Gardner \& Stough, 2002; Barling, Slater \& Kelloway, 2000; Cherniss, 2000; Cooper \& Sawaf, 1997; Mayer \& Salovey, 1997; Salovey \& Mayer, 1990) described above demonstrated that leaders need emotional intelligence skills. The need to better identify the particular features that form these capacity requirements and to understand how those capacities are produced is one of the most notable research gaps. The research has also indicated the necessity for educational leadership development programs to improve the ability of learners to engage all stakeholders with emotional intelligence. For these reasons, it is conceptualized a more comprehensive hermeneutic phenomenological study of the accounts of individual leaders using narrative investigation techniques and means to better understand how their emotional intelligence development and application affects their respective departmental communities.

The aim of this hermeneutic phenomenological study was to describe and evaluate the experiences of department heads in terms of their understanding, acquisition, and growth of emotional competence, as well as their use of emotional competence in their profession to impact their department community. Specifically, it was possible to study how participants describe successfully making positive changes by conducting in-depth interviews, transcribing those interviews and then interpreting their life texts and, if possible, making adaptations to their professional practice by understanding, developing and using their personal emotional capacity. It also determined if participants had better informed and had a beneficial influence on both their professional careers and the careers of existing and aspiring managers by providing greater training in emotional competence. The study intended to uncover similar, different themes and subjects in their experiences and to improve the achievements of present and future leaders via the application of emotional competence behaviors.

The study attempted to determine if leaders view knowledge, growth and use of emotional competence in their professional repertoire as essential and required elements. This study was guided by the following questions:

- What are the perspectives of heads of departments on their knowledge, acquisition, growth, and use of emotional competence skills?

- What kind of emotional competence experience do heads of departments have in leading their 
departments?

\section{Method}

Using interpretative narrative inquiry techniques and tools, this study utilized a hermeneutic phenomenological method to help with the organizing and interpretation of qualitative data. In the study of human cultural activity, hermeneutic phenomenology is concerned with the examination of texts (Laverty, 2003). The researcher wanted to investigate how participants saw their emotional competence and how they employed it in many parts of their organizations. Furthermore, this phenomenon was investigated by searching for recurring themes in participants' transcripts from the occurrences of each participant's narrative, which utilized the methodology of narrative inquiry and the tools of narrative analytics. The design and method were also appropriate for the sample size used. Open-ended questions were used to gather information on their professional practice, recordings of participants' voices were made, transcribed recordings were made, and behavioral and nonverbal responses were noted. Narrative inquiry tools include specialized templates, such as the Thematic Data Summary Sheets, Plot Analysis, and Significance Analysis templates, for data organization and analysis. The research was designed with the usage of templates in mind. Using narrative inquiry templates was intended to supply deeper insight and meaning for those who want to know more about the "experts" who have demonstrated the ability to integrate emotionally intelligent capacities into their repertoire of interpersonal skills.

Purposeful sampling is a technique widely used in qualitative research for the identification and selection of information-rich cases for the most effective use of limited resources (Patton, 2002). This involves identifying and selecting individuals or groups of individuals that are especially knowledgeable about or experienced with a phenomenon of interest (Cresswell, 2013). In addition to knowledge and experience, Bernard and Ryan (2010) note the importance of availability and willingness to participate, and the ability to communicate experiences and opinions in an articulate, expressive, and reflective manner.

Purposive sampling was utilized for eight heads of departments in a public university in Izmir, Turkey in the 2019-2020 academic year, with a focus on phenomena of relevance to the topic and at least four years of administration experience in choosing criteria. These individuals were either nominated for inclusion by themselves or were suggested by other participants. The interviews were recorded and lasted an average of one hour and fifteen minutes. The small sample size prevents generalization of findings, but the research design allows for illustration of how department heads' use of emotional competence relates to the larger body of emotional competence research.

A procedure was created to be used by the research participants after testing, modifying, and extending the number of interview questions. It included interpretative one-on-one interviews that were taped and analyzed later. The interviews had at least one hour meeting with each head of department. The participants were told that if they needed more information, they could schedule follow-up meetings. The interview transcripts were transcribed and examined for similar and different subjects and themes in the participants' experiences, as well as to see if these administrators saw emotional competence, knowledge, growth, and usage as essential components of their professional careers. The transcripts of the participants were analyzed and summarized using a qualitative hermeneutic phenomenological analysis method, which was guided by narrative analytical techniques and tools (Daiute, 2014).

Besides the plot analysis and the significant markers templates, four other analytical tools were used: theme data summary sheets, condensed thematic data summary sheets, the plot analysis, and the significance markers templates. During the interviews, participants were allowed to express their knowledge of emotional competence in a variety of ways, either directly or indirectly. Participants primarily demonstrated their comprehension when they discussed the interpersonal and intrapersonal skills that they needed to possess, as well as the strategies that they employed, in order to provide direction to others and influence the academic achievement of their participating university. After reviewing the recordings of the participants and thematic data summary sheets, plot analysis template, and significant markers template were created to help with the interpretation of the data.

\section{Results}

The main research question was "What are the perspectives of heads of departments on their knowledge, acquisition, growth, and use of emotional competence skills?" and it sought to find out how far participants could go in their awareness of emotional competence. For this topic, the theme was derived largely from participants' narratives and interviews with participants, as well as a more in-depth examination of the results. 


\subsection{Main Theme}

\subsubsection{The Ability to Develop Connections by Generating Trust in Order to Lead the Department}

Many of the participants' interview progressions have a number of common theme features. When participants recounted the accomplishments they had at their universities, a pattern of similar components emerged. To achieve this goal, "they needed to increase their participation in school-based activities that were new to them, and/or maintain established relationships in their departments where they already had a presence"; "they were responsible for restoring order by negotiating through respectful conversation a department issue, which enabled them to first understand and appreciate other people's views on the matter"; "they were in charge of generating a shared belief system by opening themselves to finding a mutually-agree.

HD 1 began by stating the following:

"To put it another way, you just have to learn this through time: take the people you have, appreciate the people you have, and they will work for you. In exchange for your respect for them and their opinions, they want to work for you."

HD 6 stated that:

"Assuming, for example, that we have reached an agreement, but that the basis of emotional competence has not been established right from the start by asking individuals what is essential to them... In the absence of taking the time to do so, and valuing their input as you go through your problems, and there will be struggles, they will just be oppositional and belligerent.... It's simply a struggle between coming in and accomplishing what you actually need to do and staying out of trouble."

HD 6 shared his perspective of emotional intelligence by noting that:

"Any good learning will take place when there is a worthwhile relationship...truly that's what this is accomplishing." This is the process of establishing partnerships among stakeholders. When you do so relationships are formed, and then the task may be completed successfully."

During the interviews, it was seen that the heads of departments stressed the importance of earning the trust of lecturers, students and staff members, as well as developing connections with these stakeholders, before embarking on the crucial task. Regarding contractual difficulties, HD 5 emphasized

"How far she had come with her present crew "I know I'm not a member of your aspect, but I'm kind a member of your thought, in another way," she reported, which has gotten them to really, I believe, trust me, and if they notice something is wrong, even some of my strongest, most assertive personalities, who wouldn't go to the administrator..."

Throughout HD 3's account,

"The best faculty members are handled like the manager would like to be treated. The members of the organizations will serve you. It is important to value them, and if you show that you value them, they will want to continue to work with you. While the day was coming to a conclusion, I would get a surge of energy, work on a few more tasks, and make significant progress."

Each participant stated that they had made several attempts to establish confidence with their faculties as well as to establish and/or maintain connections with them. Through the analysis of the participants' personal narratives and the associated templates, it was found that emotional competence is widely defined as the ability to develop connections and generate trust in order to lead the department.

\subsection{Subthemes}

The sub-research question was "What kind of emotional competence experience do heads of departments have in leading their departments?" and it sought crucial experience related to their emotional competencies in leading their departments. All of the participants' narratives had a common thread that stressed the necessity of building relationships with others by using emotional competence. The following provide discussions of the subthemes that one or more of the participants believe are crucial for the success of relationships. In particular, they comprise the abilities to be open, to be positive, to be respectful, to be inclusive and to be an active listener.

\subsubsection{Having an Open Mind}

Having an open mind was interpreted by participants as an essential strategy for engaging stakeholders and for sharing ideas on how to improve school. In other words, remarks, as stated by HD 3, and HD 6, express a willingness to have productive conversations in order to affect good change. HD 3 said: 
"When it comes to people's ideas, I think it is really essential to be open to new ideas, but I also feel it is quite vital to demonstrate to others that if they put in the time and effort to develop a concept, we will do it."

It was observed that each of the participants' recommendations on how to enhance school included a statement about openness. Participants expressed their high value on openness by using it as a communication skill.

\subsubsection{Having an Optimistic Attitude}

Having an optimistic attitude is another subtheme. Participants went so far as to characterize the trait of being optimistic as helping them to better comprehend emotional competence, especially when it came to trying out new teaching methods.

HD 8 stated that:

"That's our goal. Achieve greatness. Thank you everybody for being good. This is an opportunity to move to a fantastic location for your students."

Participants' reports show that they interpreted emotional competence to involve the need to be positive with faculty, particularly when faculty are attempting new teaching techniques, as revealed by the reports. Participants were unanimous in their belief that it was essential to place a positive emphasis on students' achievements rather than a negative emphasis on instructors' ineffectiveness.

\subsubsection{Being Respectful}

Being respectful is crucial in all activities of the administrators. Participants' responses stressed the need to listen to and respect the opinions of others, particularly within the larger school community, school committees, and other administrative staff. Several instances of politely asking and taking into account all viewpoints from all stakeholders were provided by each speaker. Whenever they were discussing how to move forward with any significant school success program, this was very evident.

HD1's report demonstrated his dedication to taking into consideration the ideas and opinions of the whole school community. According to this passage, he considered "voice" and what might happen as a result of failing to pay attention to those around him:

"I believe that we are all learners, ... being courteous to one another and learning from one another. We are all in the process of learning something new."

Respect for others is an important component of emotional competency for all participants. During their narrative, HD 2 and HD 5 both made reference to "the basic principle," and both called for the use of this measure to treat others in the same manner that one would expect to be treated.

\subsubsection{To be Inclusive}

Inclusivity arises in the narratives and explanations of each participant. A number of participants shared their strategies for building relationships with people in the school community, particularly lecturers. These strategies include talking with faculty members and connecting with other students. Using narrative analysis, it was discovered that participants appreciated faculty, and all of them were dedicated to building inclusive communities with faculty members. Each participant discussed strategies to establish cohesive, collaborative, and communal school bodies, as demonstrated in the following instance.

HD 1 said that

"Highly inclusive administrators view the process of distributing work as a joint effort between the leader and team member. Employees are given the chance to work on projects that interest them, and they are given challenging responsibilities. People are asked for their opinion before tasks are sent out in order to make it work efficiently."

This demonstrates that inclusive administrators carefully assess the work distribution process, considering each team member's interests as well as their abilities. They make sure that everyone gets to work on projects that they're interested in. This group gathers suggestions from people prior to making assignments in order to make sure that everyone is on the same path.

\subsubsection{Listening Actively}

Listening actively is a process rather than a one-time action. Participants shared a similar set of thoughts on the value of paying attention as a school administrator. In the end, it was discovered that participants place a high value on this skill and that it is critical to their total emotional competence. 
According to HD 8,

"A tendency for noticing voices and this has been noted by others as part of her character."

HD 2 stated that

"It is not just being kind, but also ensuring that others feel good. An atmosphere that honours each person's feelings and accommodates real conversations about differing views and real listening is what we're aiming for."

The findings were consistent in showing participants' perception of the importance of listening in emotional competence. The participants agreed that listening actively competency was critical to their positions. The narratives of all of the participants shared a common thread that emphasized the need to develop relationships with others while demonstrating emotional competence.

\section{Discussion}

This study was conducted to define and evaluate emotional competence among administrators at a public higher education institution and to examine whether types of competence experiences are relevant for advancing professional development. Academic leaders are expected to be strategic and inventive in their work, regardless of the context. Leaders must interact with a diverse group of individuals to meet these expectations. On the other hand, they must work in a hectic, busy workplace, under intense deadlines, with higher expectations of responsibility, in a period when funding or resources are either decreasing or stagnant. Academic leaders and their teams might experience a wide range of emotions as a result of these experiences, which include irritation, anger, and excitement. Several research (Mayer \& Salovey, 1997; Barling \& Kelloway, 2000; Bauman, 2006; Goleman, 2006; Beytekin \& Göktürk, 2012) were done with regard to working environments and job happiness, and it was shown that emotional self-efficacy is heightened when leaders follow the concepts of emotional competence in their everyday leadership activities. In order to be a successful leader, one must possess a high level of emotional competence. A person with good training, an acute, analytical mind, and an inexhaustible supply of clever ideas will not necessarily be a great leader, as long as he or she lacks the skills of emotional competence.

This study's most noteworthy finding was that university administrators reported needing deep personal ties in order to have a clear understanding of their emotional competency. It was found that the individuals' success experiences tended to be rather similar; these narratives all seemed to involve academic accomplishment and emotional competence in their department. As well as the need to build trusting connections, concerns are expressed about the techniques used to achieve emotional competence. The participants also implied how they resolved conflicts and increased communication by being emotionally competent to one another. They went on to explain how they implemented agreed-upon beliefs by being open, finding a resolution to the problem, and then acting on their plans. It has been demonstrated throughout prior studies that emotional competence is necessary for administrators to manage their duties (Akyol \& Arslan, 2014; Gumport \& Sporn, 1999). Such basic and distinct subjects and topics as well as life texts and narrative inquiry tools and techniques that can help these leaders better comprehend how their profession has been influenced and developed by way of emotional competence, growth, and change have been revealed during their experiences being captured by them as well as the ensuing interpretations of those experiences. This information may influence higher education by providing additional basic assistance that may help an administrator create, use and comprehend the function of emotional ability in their repertoire of important professional practices. This study was designed to help higher education leaders obtain an awareness of the development and utilization of emotional skills necessary for a positive effect on the management of their business. In addition, the research findings on the application of emotional skills by administrators are connected with the broader body of educational administration settings. In order for all educational leaders to be effective, emotional competence must be included in their repertoire of leadership strategies and techniques. Emotions play a key role in the choices people make and the level of involvement they have with their institutions. However, when higher education leaders understand this, possibilities open up to build on that vision of potential and to help their institutions succeed in moving to new levels of success.

The design of coursework in preparation for a leadership position should focus on developing competency in four areas: emotional, social, personal, and professional. Work through the methods of development described for each framework, and it was proposed that educational leaders could use the emotional competence they had developed to improve their schools by closing the gap in understanding between themselves and others, developing action plans, and creating connections. The heads of departments agreed that, despite the fact that they had not received any formal training during their careers, a more organized training program would be beneficial to individuals aiming for positions of leadership. As a consequence of this research, it has been 
concluded that emotional competence, being open, being positive, being respectful, being inclusive and being an active listener and leadership are all relevant concepts, and in order to more accurately define their place within the overall foundation, they need to be built on a more cohesive theoretical framework.

\section{References}

Akyol, B., \& Arslan, H. (2014). The evaluation of higher education problems in Turkey. European Scientific Journal, 10(7), 71-84. https://doi.org/10.19044/esj.2014.v10n7p\%25p

Bar-On, R. (2013) The Bar-On concept of EI. Reuven Bar-On.org. Retrieved from http://www.reuvenbaron.org/wp/the-bar-on-model/the-ei-conceptual-aspect

Barling, J., Slater, F., \& Kelloway, E. K. (2000). Transformational leadership and emotional intelligence: An exploratory study. Leadership and Organization Development Journal, 21(3), 157-161. https://doi.org/10.1108/01437730010325040

Bauman, D. (2006). The relationship between the emotional competence and the leadership effectiveness of hall directors. University of Missouri-Columbia.

Bernard, H. R., \& Ryan, G. W. (2010). Analyzing qualitative data: Systematic approaches. Los Angeles Calif.: SAGE.

Beytekin, O. F., \& Göktürk, S. (2012). Administrative Behaviors and Emotional and Social Competences of Higher Education Administrators: A Cross-Cultural Study. Journal of Higher Education and Science, 2(1), 33-42. https://doi.org/10.5961/jhes.2012.031

Boyatzis, R. E., Goleman, D., \& Rhee, K. (1999). Clustering competence in emotional intelligence: Insights from the emotional competence inventory. In R. Bar-On \& D. A. Parker (Eds.), Handbook of Emotional Intelligence. San Francisco: Jossey Bass.

Boyatzis, R. E., \& Oosten, E. V. (2002). Developing emotionally intelligent organizations. R. Millar (Ed.), International Executive Development Programmes, 7th Edition. London: Kogan Page Publishers.

Cherniss, C. (2000). Emotional Intelligence: Why it is and why it Matters. Paper presented at the Annual Meeting of the Society for Industrial and Organizational Psychology, New Orleans.

Cooper, R., \& Sawaf, A. (1997). Executive EQ. emotional intelligence in leadership and organizations. NY: The Berkley Publishing Group.

Crabtree, B. F., \& Miller, W. L. (1992). Doing qualitative research: multiple strategies. Thousand Oaks, CA: Sage Publications.

Creswell, J. W. (2013). Qualitative inquiry and research design: Choosing among five traditions (3rd ed.). Thousand Oaks, CA: Sage.

Daiute, C. (2014). Narrative inquiry: A dynamic approach. Thousand Oaks, CA: Sage. https://doi.org/10.4135/9781544365442

Gardner, L., \& Stough, C. (2002). Examining the relationship between leadership and emotional intelligence in senior level managers. Leadership and Organization Development Journal, 23(2), 68-78. https://doi.org/10.1108/01437730210419198

Goleman, D. (2013). The Focused Leader. Harvard Business Review, 91(12), 50-60.

Goleman, D. (2006). Emotional intelligence. London: Bloomsbury Publishing.

Gumport, P. J., \& Sporn, B. (1999). Institutional adaptation: Demands for management reform and university administration. In J. Smart (Ed.), Higher Education: Handbook of Teaching and Research. NY: Agathon Press.

Hoy, W. K., \& Miskel, C. G. (2010). Management Theory, Research and Practice. In S. Turan (Ed.), Çev. Ankara: Nobel.

Kezar, A., Lester, J., Carducci, R., Gallant, T. B., \& MCGavin, M. C. (2007). Where are the faculty leaders, Liberal Education Fall, 14-21.

Knight, P. T., \& Trowler, P. R. (2001). Departmental leadership in higher education, London: SRHE and Open University Pres.

Laverty, S. (2003). Hermeneutic phenomenology and phenomenology: A comparison of historical and methodological considerations. International journal of qualitative methods, 2(3), 21-35. 
https://doi.org/10.1177/160940690300200303

Schreiber, O., Lichtenstein, B. B., Uhl-Bien, M., \& Schreiber, C. (2006). Complexity leadership theory: an interactive perspective on leading in complex adaptive systems. E:Co, 8(4), 2-12.

Mayer, J. D., \& Salovey, P. (1997). What is emotional intelligence? In P. Salovey \& D. J. Sluyter (Eds.), Emotional Development and Emotional Inteligence. Newyork: Basic Books.

Miles, M. B., \& Huberman, A. M. (1994). Qualitative data analysis (2nd ed.). Thousand Oaks, CA: Sage.

Patton, M. Q. (2001). Qualitative research and evaluation methods (3rd ed.). Thousand Oaks, CA: Sage.

Sternberg, R. (2000). Handbook of Intelligence. Cambridge, UK: Cambridge University Press. https://doi.org/10.1017/CBO9780511807947

Winston, R. B., Creamer, D. G., \& Miller, T. K. (2001). The professional student affairs administrator: Educator, leader, and manage. NY: Taylor \& Francis.

\section{Copyrights}

Copyright for this article is retained by the author(s), with first publication rights granted to the journal.

This is an open-access article distributed under the terms and conditions of the Creative Commons Attribution license (http://creativecommons.org/licenses/by/4.0/). 